\title{
Synthesis of chiral 2-methyl-5,6,7,8-tetrahydroquinolines from naturally occurring monoterpenes
}

\author{
Giorgio Chelucci,* Gianmauro Orrù, and Franco Soccolini \\ Dipartimento di Chimica, Università di Sassari, via Vienna 2, I-07100 Sassari, \\ Italy \\ E-mail: chelucci@ssmain.uniss.it
}

(received 17 Mar 04; accepted 09 Aug 04; published on the web 22 Aug 04)

\begin{abstract}
The synthesis is reported of chiral substituted 2-methylpyridines, in which the pyridine rings are annulated at the 5,6-positions to the chiral frameworks originating from (-)- $\beta$-pinene,

(-)-isopinocampheol and (+)-camphor. Two procedures have been evaluated for their preparation.
\end{abstract}

Keywords: Chiral tetrahydroquinolines, chiral pyridines, chiral nitrogen heterocycles, Kröhnke annulation

\section{Introduction}

During our study on the synthesis of chiral P,N-ligands with pyridine N-donors, ${ }^{1,2}$ we needed a set of chiral substituted 2-methylpyridines bearing a stereogenic centre on the carbon bonded to the 6-position of the heterocycle. Since these compounds should be obtained from inexpensive chiral compounds, monoterpenes, easily available building blocks originating from the chiral pool, were selected as appropriate starting materials.

Herein, we wish to report the synthesis of the three chiral substituted 2-methylpyridines 1-3 in which the pyridine rings are annulated at the 5,6-positions to chiral frameworks originating from (-)- $\beta$-pinene, (-)-isopinocampheol and (+)-camphor.

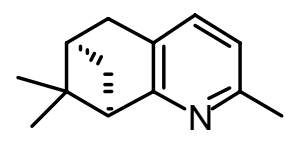

1

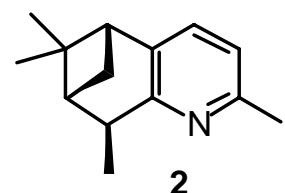

2

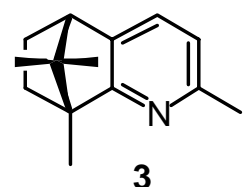

3 


\section{Results and Discussion}

At the start of our investigation, we envisaged that the most direct approach to tetrahydroquinolines 1-3 could involve the Kröhnke methodology for the synthesis of pyridines. ${ }^{3}$ This route demands the reaction of a $\beta$-ketoalkylpyridinium salt with an $\alpha, \beta$-unsaturated carbonyl compound in the presence of ammonium acetate/acetic acid. Thus, to test the feasibility of this idea, 1-(2-oxopropyl)pyridinium bromide $(\mathbf{6})^{4}$ was prepared by reaction of bromoacetone 5 with pyridine (Scheme 1).

An attempt to prepare the analogue iodide by reaction of acetone with iodine in pyridine, as reported by Saxena et al. ${ }^{5}$ failed. Instead we obtained 1,3-(dipyridinium-1-yl)propan-2-one diiodide (7) in $15 \%$ yield (Scheme 1). Salt 6 was then treated with the $\alpha$-methylene ketone $\mathbf{9}^{6}$ which was selected as a typical substrate to develop optimal reaction conditions. Compound 9 was prepared in two steps from the ketone 8 obtained in turn by oxidation of (-)- $\beta$-pinene ${ }^{7}$ (Scheme 2). The Kröhnke-type cyclization gave the expected pyridine $\mathbf{1}$ but in low yield. Although many permutations of conditions were explored, in no case the yield of the desired pyridine was $>15 \%$.

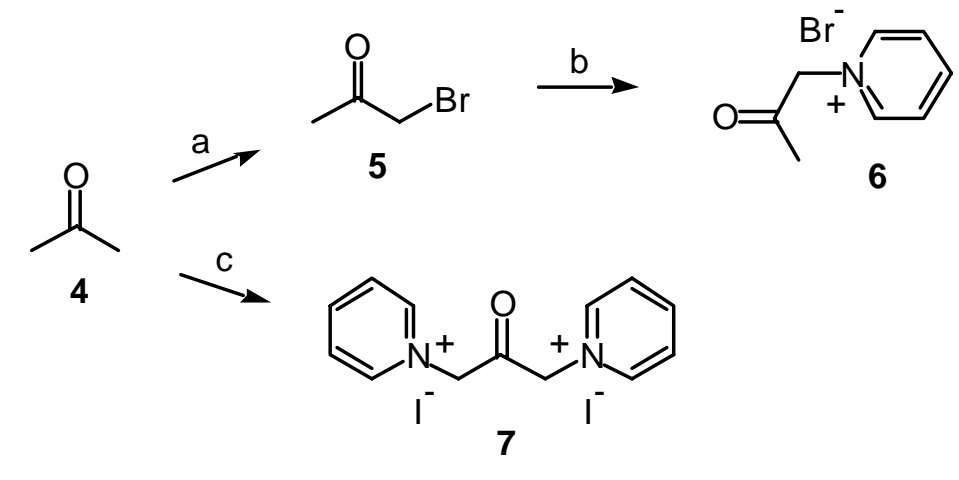

a: $\mathrm{Br}_{2}, \mathrm{Na}_{2} \mathrm{CO}_{3}, \mathrm{CCl}_{4} ;$ b: pyridine, $\mathrm{Et}_{2} \mathrm{O} ; \mathrm{c}: \mathrm{I}_{2}$, pyridine, $\mathrm{MeOH}$.

\section{Scheme 1}

The unsatisfactory outcome of these experiments prompted us to examine an alternative procedure $^{8}$ (Scheme 2). Accordingly, dimethylhydrazone 10, prepared by treatment of the $(+)$ nopinone (8) with $N, N$-dimethylhydrazine, was deprotonated ( $n$-BuLi, THF, $-78{ }^{\circ} \mathrm{C}, 2 \mathrm{~h}$ ) and then quenched with 2-(2-bromoethyl)-2,5,5-trimethyl-[1,3]dioxane (12). The alkylation product 11 was not isolated, but directly converted into the tetrahydroquinoline $\mathbf{1}$ by heating in carbitol (35\% yield based on 10). The overall yield (31\% yield based on 8 ) of this process was much higher than that obtained following the Kröhnke-type cyclization (10\% yield based on 8). Having obtained the desired pyridine 1, the alkylation-azaannulation-aromatization sequence was extended to the bicyclic ketones 14, prepared by oxidation of (-)-isopinocampheol, and (+)- 
camphor (17) (Scheme 3 and 4). Thus, the dimethylhydrazones 15 and 18, afforded pyridines 2 and 3 in 32 and $17 \%$ yield, respectively.<smiles>C=C1CC[C@@H]2CC1C2(C)C</smiles>

(-)- $\beta$-pinene

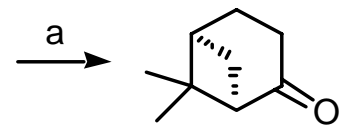<smiles>C[Tl]</smiles><smiles>CN(C)/N=C1/CC[C@H]2C[C@H]1C2(C)C</smiles>

8

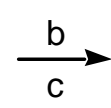

e

10<smiles>C=C1CC2CC1C(=O)C2(C)C</smiles>

9<smiles>Cc1ccc2c(n1)[C@H]1CC(C2)C1(C)C</smiles>

1<smiles>CC1C2CCC1C(CCC1(C)C[C@@H](C)C(C)(C)CO1)C2</smiles>

11

a: $\mathrm{TMO}, \mathrm{OsO}_{4}, \mathrm{Py}, t-\mathrm{BuOH} / \mathrm{H}_{2} \mathrm{O}$, then $\mathrm{NaIO}_{4}$, r.t., reflux, $2 \mathrm{~h}, 66 \%$; b: $\mathrm{NaNH}_{2}, \mathrm{Bz}$, reflux, $15 \mathrm{~h}$; then isopentyl formate, r.t., $4 \mathrm{~h}$, finally $\mathrm{HCl}$, 71\%; c: $\mathrm{Na}_{2} \mathrm{CO}_{3}, \mathrm{HCHO}$, r.t., 40 min, 99\%; d: 6, $\mathrm{MeOH}, \mathrm{AcONH}_{4}$, reflux, 20h, 15\%; e: $\mathrm{H}_{2} \mathrm{NNMe}_{2}$, EtOH, reflux; f: $n$-BuLi, THF, -78 C

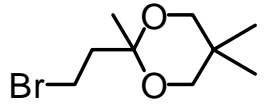

12 then 12; g: carbitol, $\mathrm{HCl}$, reflux, $6 \mathrm{~h}$.

\section{Scheme 2}

The overall yield of the process was comparable for pyridines 1 and 2 (32-35\%), but much lower $(17 \%)$ for pyridine 3 derived from camphor. This result can be attributed to the steric hindrance of the camphor carbonyl group that reduces the ability of this ketone to undergo the azaannulation step. ${ }^{9}$

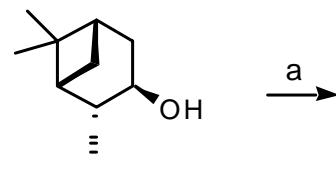

(-)-isopinocampheol 13

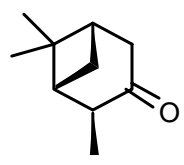

14

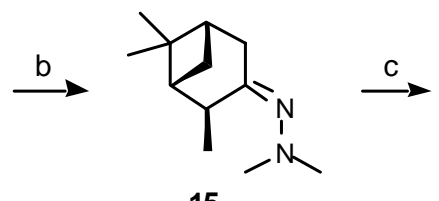

15

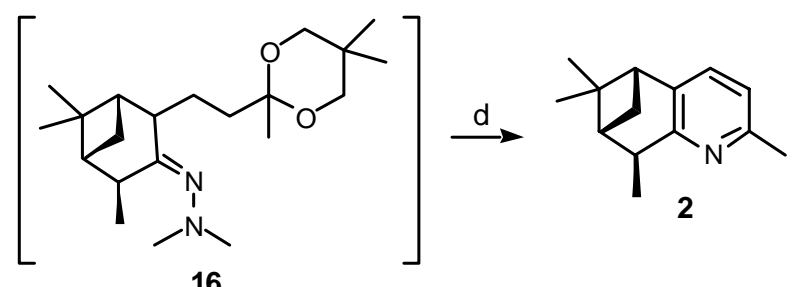

16

a: $\mathrm{CrO}_{3}, \mathrm{H}_{2} \mathrm{SO}_{4}$, acetone, $82 \%$; b: $\mathrm{H}_{2} \mathrm{NNMe}_{2}, \mathrm{EtOH}$, reflux; c: $n$-BuLi, THF, $-78{ }^{\circ} \mathrm{C}$ then 12 ;

d: carbitol, $\mathrm{HCl}$, reflux, $6 \mathrm{~h}$

\section{Scheme 3}




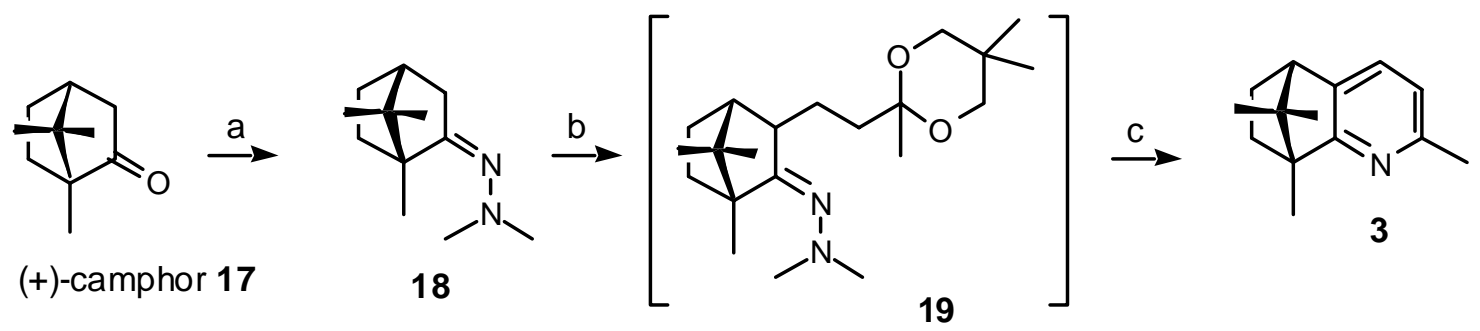

a: $\mathrm{H}_{2} \mathrm{NNMe}_{2}$, EtOH, reflux; b: $n$-BuLi, THF, $-78^{\circ} \mathrm{C}$ then 12 ; c: carbitol, $\mathrm{HCl}$, reflux, $6 \mathrm{~h}$

\section{Scheme 4}

With the pyridines 1-3 in hand, we attempted to transform them into the related pyridinephosphine ligands 20 (Scheme 5). Unexpectedly, several attempts to prepare 20 by metallation of the 2-methyl group of compounds 1-3 with various bases (LDA, $n$-BuLi, $\mathrm{PhLi}$, etc.), followed by treatment with chlorodiphenylphosphine, failed. ${ }^{10}$

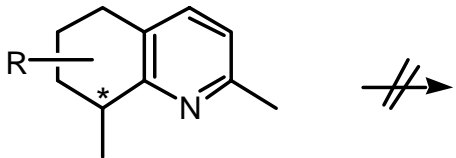

1-3<smiles>[R]CCc1ccc(CPc2ccccc2)nc1C(C)C</smiles>

20

\section{Scheme 5}

\section{Conclusions}

Although the synthesis of the pyridine-phosphines of the type $\mathbf{2 0}$ has been unsuccessful, we have explored two procedures for preparing chiral substituted 2-methylpyridines from monoterpenes, making available new chiral pyridines which could be useful chiral building blocks for the synthesis of more complex heterocycles. ${ }^{11}$

\section{Experimental Section}

General Procedures. All reagents and solvents were purchased from Aldrich and used as received. THF was distilled from sodium-benzophenone ketyl and degassed thoroughly with dry nitrogen directly before use. Melting points were determined on a Büchi 510 capillary apparatus and are uncorrected. The ${ }^{1} \mathrm{H}-\mathrm{NMR}$ spectra were obtained with a Varian VXR-300 spectrometer at $300 \mathrm{MHz}$. Chemical shifts are reported in ppm downfield from internal $\mathrm{Me}_{4} \mathrm{Si}$ in $\mathrm{CDCl}_{3}$ if not otherwise stated. Optical rotations were measured with a Perkin-Elmer 241 polarimeter in a $1 \mathrm{dm}$ tube. Elemental analyses were performed on a Perkin-Elmer 240 B analyser. 
1-(2-Oxopropyl)pyridinium bromide (6) was prepared according to a reported procedure. ${ }^{4}$ $(1 R, 5 R)-6,6$-Dimethylbicyclo[3.1.1]heptan-2-one $\quad((+)$-nopinone, 8) and $(1 R, 2 S, 5 S)-2,6,6-$ trimethylbicyclo[3.1.1] heptan-3-one (14) were prepared by oxidation of (-)- $\beta$-pinene (99\% pure, Aldrich) ${ }^{7}$ and (-)-isopinocampheol (98\% pure, 95\% ee by GLC, Aldrich), ${ }^{12}$ respectively. $(1 R, 5 R)-6,6-D i m e t h y l-3-m e t h y l e n e b i c y c l o[3.1 .1]$ heptan-2-one (9) was prepared from (+)nopinone (8). ${ }^{7}(+)$-Camphor (17) and 2-(2-bromoethyl)-2,5,5-trimethyl-[1,3]-dioxane (12) were purchased from Aldrich.

\section{General procedure for the preparation of $N, N$-Dimethylhydrazones ${ }^{13}$}

A solution of the ketone $(0.02 \mathrm{~mol}), N, N$-dimethylhydrazine $(2.7 \mathrm{~g}, 0.045 \mathrm{~mol})$ and catalytic amount of 4-toluenesulfonic acid in absolute EtOH $(25 \mathrm{~mL})$ was heated under reflux for 7 days. The solvent was removed and the residue taken up with cold $\left(0{ }^{\circ} \mathrm{C}\right) 5 \% \mathrm{HCl}(2 \times 15 \mathrm{~mL})$ and $\mathrm{Et}_{2} \mathrm{O}(20 \mathrm{~mL})$. The aqueous layer was separated, basified with $10 \%$ solution of $\mathrm{NaOH}(40 \mathrm{~mL})$ and extracted with $\mathrm{Et}_{2} \mathrm{O}(2 \times 20 \mathrm{~mL})$. The organic extracts were dried over anhydrous $\mathrm{Na}_{2} \mathrm{SO}_{4}$ and the solvent was evaporated. The residue was purified by distillation under reduced pressure to give pure $N, N$-dimethylhydrazones.

(1R,5R)- $N, N$-Dimethyl- $N^{\prime}-(6,6$-dimethylbicyclo[3.1.1]hept-2-ylidene) hydrazine (10). This compound was obtained in 93\% yield based on the converted ketone 8: bp $100{ }^{\circ} \mathrm{C}(10 \mathrm{~mm} \mathrm{Hg})$, ${ }^{1} \mathrm{H}-\mathrm{NMR}: \delta$ 2.65-2.42 (m, 3H), 2.45 (s, 6H), 2.30-1.80 (m, 4H), 1.43 (d, 1H, J = 9.9 Hz), 1.28 (s, $3 \mathrm{H}), 0.78$ (s, 3H). Calcd for $\mathrm{C}_{11} \mathrm{H}_{20} \mathrm{~N}_{2}$ : C, 73.28; H, 11.18; N, 15.54. Found: C, 73.32; H, 11.14; $\mathrm{N}, 15.51$.

(1R,2S,5S)- $N, N$-Dimethyl- $N$ '-(2,6,6-trimethylbicyclo[3.1.1]hept-3-ylidene) hydrazine (15). This compound was obtained in $93 \%$ yield based on the converted ketone 14 : bp $115{ }^{\circ} \mathrm{C}(10 \mathrm{~mm}$ Hg), ${ }^{1} \mathrm{H}-\mathrm{NMR}: \delta$ 2.88-280 (m, 1H), 2.75-2.68 (m, 2H), $2.46(\mathrm{~s}, 6 \mathrm{H}), 2.31-2.22(\mathrm{~m}, 1 \mathrm{H}), 2.02-$ $1.91(\mathrm{~m}, 1 \mathrm{H}), 1.86-1.78(\mathrm{~m}, 1 \mathrm{H}), 1.25(\mathrm{~s}, 3 \mathrm{H}), 1.18(\mathrm{~d}, 3 \mathrm{H}, \mathrm{J}=7.2 \mathrm{~Hz}), 1.08(\mathrm{~d}, 1 \mathrm{H}, \mathrm{J}=10.5 \mathrm{~Hz})$, 0.83 (s, 3H). Anal. Calcd for $\mathrm{C}_{12} \mathrm{H}_{22} \mathrm{~N}_{2}$ : C, 74.17; H, 11.41; N, 14.42. Found: C, 74.22; H, 11.48; $\mathrm{N}, 14.38$.

$N, N$-Dimethyl- $N^{\prime}-(1,7,7$-trimethylbicyclo[2.2.1]hept-2-ylidene)hydrazine $\quad$ (18). This compound was obtained in $87 \%$ yield based on the converted camphor: bp $65{ }^{\circ} \mathrm{C}(4 \mathrm{~mm} \mathrm{Hg}),{ }^{1} \mathrm{H}-$ NMR: $\delta$ 2.58-2.47 (m, 1H), $2.45(\mathrm{~s}, 6 \mathrm{H}), 2.00(\mathrm{~d}, 1 \mathrm{H}, \mathrm{J}=18 \mathrm{~Hz}), 1.93-1.76(\mathrm{~m}, 2 \mathrm{H}), 1.68(\mathrm{dt}$, $1 \mathrm{H}, \mathrm{J}=12,4 \mathrm{~Hz}), 1.37(\mathrm{dt}, 1 \mathrm{H}, \mathrm{J}=12,4 \mathrm{~Hz}), 1.21(\mathrm{dt}, 1 \mathrm{H}, \mathrm{J}=12,4 \mathrm{~Hz}), 1.03$ (s, 3H), 0.97 (s, $3 \mathrm{H}), 0.82(\mathrm{~s}, 3 \mathrm{H})$. Calcd for $\mathrm{C}_{12} \mathrm{H}_{22} \mathrm{~N}_{2}$ : Anal. Calcd for $\mathrm{C}_{12} \mathrm{H}_{22} \mathrm{~N}_{2}$ : C, 74.17; H, 11.41; N, 14.42. Found: C, 74.12; H, 11.37; N, 14.47.

1,3-(Dipyridinium-1-yl)propan-2-one diiodide (7). A solution of iodine (101.6 g, $0.4 \mathrm{~mol}$ ) acetone $(29.3 \mathrm{~mL}, 0.4 \mathrm{~mol})$, pyridine $(80.9 \mathrm{~mL}, 1.0 \mathrm{~mol})$ in $\mathrm{MeOH}(600 \mathrm{~mL})$ was heated under reflux for $10 \mathrm{~h}$. The formed solid was filtered off and recrystallized from $50 \%$ aqueous methanol to give white crystals: $14.0 \mathrm{~g}$ (15\% yield based on the iodine), mp $227-228{ }^{\circ} \mathrm{C}$. ${ }^{1} \mathrm{H}-\mathrm{NMR}$ $\left(\left(\mathrm{CD}_{3}\right)_{2} \mathrm{SO}\right): \delta 8.72(\mathrm{~d}, 4 \mathrm{H}, \mathrm{J}=5.4 \mathrm{~Hz}), 8.75(\mathrm{t}, 2 \mathrm{H}, \mathrm{J}=7.8 \mathrm{~Hz}), 8.75(\mathrm{t}, 4 \mathrm{H}, \mathrm{J}=6.9 \mathrm{~Hz}), 6.02(\mathrm{~s}$, $4 \mathrm{H})$. Anal. Calcd for $\mathrm{C}_{13} \mathrm{H}_{14} \mathrm{I}_{2} \mathrm{~N}_{2} \mathrm{O}$ : C 33.36, H 3.01, N 5.98. Found: C 33.45, H 3.09, N 5.68. 


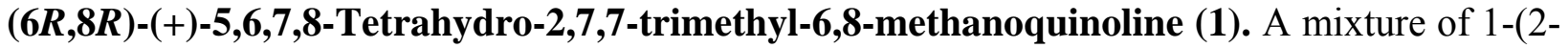
oxopropyl)pyridinium bromide (6) $(2.16 \mathrm{~g}, 0.01 \mathrm{~mol})$, ammonium acetate $(7.7 \mathrm{~g}, 0.1 \mathrm{~mol})$ and $(1 R, 5 R)$-6,6-dimethyl-3-methylenebicyclo[3.1.1] heptan-2-one (9) (1.5 g, $0.01 \mathrm{~mol})$ in absolute $\mathrm{MeOH}(50 \mathrm{~mL})$ was heated under reflux for $20 \mathrm{~h}$. After cooling the solvent was evaporated and the residue was taken up in $\mathrm{H}_{2} \mathrm{O}(200 \mathrm{~mL})$ and extracted with $\mathrm{Et}_{2} \mathrm{O}(3 \times 30 \mathrm{~mL})$. The ethereal phase was extracted with a $10 \%$ solution of $\mathrm{HCl}(3 \times 10 \mathrm{~mL})$. The aqueous phase was basified with a $10 \%$ solution of $\mathrm{NaOH}(40 \mathrm{~mL})$ and extracted with $\mathrm{Et}_{2} \mathrm{O}(2 \times 50 \mathrm{~mL})$. The combined organic phases were dried over anhydrous $\left(\mathrm{Na}_{2} \mathrm{SO}_{4}\right)$, the solvent was evaporated and the residue was purified by flash chromatography (petroleum ether/ethyl acetate $=9 / 1$ ) to give pure $\mathbf{1}$ as a pale yellow oil: $0.28 \mathrm{~g}(15 \%),[\alpha]_{\mathrm{D}}^{25}\left(\mathrm{c}=3.12, \mathrm{CHCl}_{3}\right):-25.3 .{ }^{1} \mathrm{H}-\mathrm{NMR}: \delta 7.21(\mathrm{~d}, 1 \mathrm{H}, \mathrm{J}=6.9$ $\mathrm{Hz}), 6.84(\mathrm{~d}, 1 \mathrm{H}, \mathrm{J}=6.9 \mathrm{~Hz}), 2.87(\mathrm{t}, 1 \mathrm{H}, \mathrm{J}=5.7 \mathrm{~Hz}), 2.80(\mathrm{~s}, 2 \mathrm{H}), 2.64-2.57(\mathrm{~m}, 1 \mathrm{H}), 2.40(\mathrm{~s}$, $3 \mathrm{H}), 2.25-2.20(\mathrm{~m}, 1 \mathrm{H}), 1.32(\mathrm{~s}, 3 \mathrm{H}), 1.18(\mathrm{~d}, 1 \mathrm{H}, \mathrm{J}=9.6 \mathrm{~Hz}), 0.58(\mathrm{~s}, 3 \mathrm{H}) .{ }^{13} \mathrm{C}$ NMR: $\delta 169.2$, $153.1,137.7,127.8,120.1,52.3,49.4,46.5,33.3,34.4,24.5,23.2$, 19.2. Anal. Calcd for $\mathrm{C}_{13} \mathrm{H}_{17} \mathrm{~N}$ : C 83.37, H 9.15, N 7.48. Found: C 83.46, H 9.17, N 7.50.

\section{General procedure for the preparation of chiral 2-methyl-5,6,7,8-tetrahydroquinolines}

A solution of the proper $N, N$-dimethylhydrazone $(0.02 \mathrm{~mol})$ in anhydrous THF $(5 \mathrm{~mL})$ was added dropwise to a cooled $\left(-78{ }^{\circ} \mathrm{C}\right)$ solution of $n$-butyllithium $(0.02 \mathrm{~mol}, 12.5 \mathrm{~mL}$ of a $1.6 \mathrm{M}$ solution in hexane) in anhydrous THF $(50 \mathrm{~mL})$. The resulting solution was stirred at $-78{ }^{\circ} \mathrm{C}$ for 2 $\mathrm{h}$ and then at $0{ }^{\circ} \mathrm{C}$ for $1 \mathrm{~h}$. After cooling at $-78{ }^{\circ} \mathrm{C}$, a solution of 2-(2-bromoethyl)-2,5,5trimethyl-[1,3]dioxane (12) (5.47 g, $0.02 \mathrm{~mol})$ in anhydrous THF (5 mL) was added dropwise. After $15 \mathrm{~min}$ at $-78{ }^{\circ} \mathrm{C}$, the solution was allowed to reach slowly room temperature (overnight) and were then quenched with $\mathrm{H}_{2} \mathrm{O}$. The mixture was extracted with ethyl ether. The organic phase was separated, dried $\left(\mathrm{Na}_{2} \mathrm{SO}_{4}\right)$ and the solvent was evaporated. The flask was connected to a distillation head and heated under reduced pressure $(0.1 \mathrm{~mm} \mathrm{Hg})$ to distill off unconverted hydrazone and dioxane. The residue was taken up with carbitol $(30 \mathrm{~mL})$, acidified with a few drops of $\mathrm{HCl}$ and heated under reflux for $6 \mathrm{~h}$. After cooling, the mixture was taken up with $\mathrm{H}_{2} \mathrm{O}$ $(500 \mathrm{~mL})$ and extracted with ethyl ether $(3 \times 50 \mathrm{~mL})$. The ethereal phase was extracted with a $10 \%$ solution of $\mathrm{HCl}(3 \times 50 \mathrm{~mL})$. The aqueous phase was basified with a $10 \%$ solution of $\mathrm{NaOH}$ and extracted with ethyl ether. The organic phase was dried on anhydrous $\mathrm{Na}_{2} \mathrm{SO}_{4}$, and the solvent was evaporated. The residue was distilled under reduced pressure (13 $\mathrm{mm} \mathrm{Hg}$ ) collecting the fraction distilling between $160-180{ }^{\circ} \mathrm{C}$. The distillate was finally purified by flash chromatography (petroleum ether/ethyl acetate $=9 / 1$ ) to give pure tetrahydroquinolines.

(6R,8R)-(+)-5,6,7,8-Tetrahydro-2,7,7-trimethyl-6,8-methanoquinoline (1). Yield: $1.31 \mathrm{~g}$ $(35 \%)$. The ${ }^{1} \mathrm{H}-\mathrm{NMR}$ spectrum was identical to that obtained in the above reported method.

(5R,7R,8S)-(-)-5,6,7,8-Tetrahydro-2,6,6,8-tetramethyl-5,7-methanoquinoline (2). Yield: $1.28 \mathrm{~g}(32 \%)$, oil, $[\alpha]_{D}^{25}\left(c=1.18, \mathrm{CHCl}_{3}\right):-0.61 .{ }^{1} \mathrm{H}-\mathrm{NMR}: \delta 7.06(\mathrm{~d}, 1 \mathrm{H}, \mathrm{J}=7.5 \mathrm{~Hz}), 6.81(\mathrm{~d}$, $1 \mathrm{H}, \mathrm{J}=7.5 \mathrm{~Hz}$ ), 3.21-3.10 (m, 1H), 2.68 (q, 1H, J = 6.3 Hz), 2.55-2.44 (m overlapping, 1H), 2.51 (s, 3H), 2.16-2.08 (m, 1H), 1.39 (s, 3H), 1.37 (d, 3H, J = 7.2 Hz), 1.28 (d, 1H, J = 9.9 Hz), 0.62 
(s, 3H). ${ }^{13} \mathrm{C}$ NMR: $\delta$ 168.9, 154.2, 137.4, 128.5, 119.9, 56.5, 49.8, 45.3, 33.5, 31.2, 25.3, 24.8, 21.9, 21.3. Anal. Calcd for $\mathrm{C}_{14} \mathrm{H}_{19} \mathrm{~N}$ : C 83.53, H 9.51, N 6.96. Found: C 83.61, H 9.53, N 6.94.

(5S,8R)-(+)-5,6,7,8-Tetrahydro-2,8,9,9-tetramethyl-5,8-methanoquinoline (3). ${ }^{8}$ Yield: $0.68 \mathrm{~g}$ $(17 \%)$, oil, $[\alpha]_{D}^{20}\left(c=1.44, \mathrm{CHCl}_{3}\right):+23.2 .{ }^{1} \mathrm{H}-\mathrm{NMR}: \delta 7.22(\mathrm{~d}, 1 \mathrm{H}, \mathrm{J}=7.2 \mathrm{~Hz}), 6.80(\mathrm{~d}, 1 \mathrm{H}, \mathrm{J}=$ $7.2 \mathrm{~Hz}), 2.79(\mathrm{~d}, 1 \mathrm{H}, \mathrm{J}=4.2 \mathrm{~Hz}), 2.51(\mathrm{~s}, 3 \mathrm{H}), 2.13-2.03(\mathrm{~m}, 1 \mathrm{H}), 1.83$ (dt, 1H, J = 12.3, 3.6 Hz), $1.32(\mathrm{~s}, 3 \mathrm{H}), 1.26-1.04(\mathrm{~m}, 2 \mathrm{H}), 0.97(\mathrm{~s}, 3 \mathrm{H}), 0.54(\mathrm{~s}, 3 \mathrm{H}) .{ }^{13} \mathrm{C}$ NMR: $\delta$ 169.6, 153.8, 137.8, 128.1, 119.5, 56.5, 53.9, 51.0, 31.6, 26.2, 26.1, 24.1, 19.8, 19.1. Anal. Calcd for $\mathrm{C}_{14} \mathrm{H}_{19} \mathrm{~N}$ : C 83.53, H 9.51, N 6.96. Found: C 83.48, H 9.49, N 6.98.

\section{Acknowledgements}

Financial support from MIUR (PRIN 2003033857-Chiral ligands with nitrogen donors in asymmetric catalysis by transition metal complexes. Novel tools for the synthesis of fine chemicals) and from the University of Sassari is gratefully acknowledged by G. C.

\section{References}

1. For a recent review on pyridine-phosphine ligands, see: Chelucci, G.; Orrù, G.; Pinna, G. A. Tetrahedron 2003, 59, 9471.

2. Chelucci, G.; Saba, A.; Soccolini, F. Tetrahedron 2001, 57, 9989.

3. Kröhnke, F. Synthesis 1976, 1 and references therein.

4. Kröhnke, F.; Schmidt, E.; Zecher, W. Chem. Ber. 1964, 97, 1163.

5. Saxena, J. P.; Gelra, M. A. Aust. J. Chem. 1967, 20, 1171.

6. Gianini, M.; von Zelewsky, A. Synthesis 1996, 702.

7. (a) Grimshaw, N.; Grimshaw, J. T.; Juneja, H. R. J. Chem. Soc., Perkin Trans. 1 1972, 50.

(b) Brown, H. C.; Weissman, S. A.; Perumal, P. T.; Dhokte, U. P. J. Org. Chem 1990, 55, 1217.

8. Chelucci, G.; Gladiali, S.; Marchetti, M. J. Heterocyclic Chem. 1988, 25, 1761.

9. Chelucci, G.; Delogu, G.; Gladiali, S.; Soccolini, F. J. Heterocyclic Chem. 1986, 23, 1395.

10. For the method on related 2-picoline, see: Newkome, G. R. Chem. Rev. 1993, 93, 2067.

11. For references on the synthesis of chiral pyridine derivatives, see: Chelucci, G.; Thummel, R. P. Chem. Rev. 2002, 102, 3129.

12. Bessière-Chrétien, Y.; Grison, C. Bull. Soc. Chim. Fr. 1970, 3103.

13. Newkome G. R.; Fishel, D. L. J. Org. Chem. 1996, 31, 677. 